\title{
Recognition memory: A cue and information analysis
}

\author{
MICHAEL S. HUMPHREYS and JOHN D. BAIN \\ University of Queensland, St. Lucia, Queensland, Australia
}

\begin{abstract}
Recall and recognition are operationally distinct procedures, yet there is increasing evidence for the involvement of recall in recognition decisions. Although this observation is not generally disputed, there has been no agreement about the appropriate level of theoretical analysis. Our contention in this paper is that the most fundamental level of analysis is in terms of the cues used, with the next level referring to the nature of the information employed as evidence. We compare at length two dual-information models to demonstrate important differences in their cuing assumptions and the difficulty of establishing that anything more than a cue analysis is required. We conclude tentatively in support of an information distinction and devote the final section to determining whether item information is contextually descriptive or is a strength variable that merely correlates with occurrence in the experiment.
\end{abstract}

Our analysis of recognition memory starts with three observations, each of which has received substantial advocacy in the theoretical literature.

1. In the recognition memory task, the subject is required to identify an item as having occurred in a particular situation or context. This observation seems to be widely accepted (see Anderson \& Bower, 1972, Bahrick, 1979, and Geiselman \& Bjork, 1980), although it should probably be limited to already familiar material. With familiar material, subjects cannot simply decide that they have encountered the material previously (this is the type of judgment that is asked for in the lexicaldecision task) but, rather, must decide that they have encountered it in a specified context.

2. Operationally, recognition differs from recall in that the to-be-recognized (TBRg) item is physically present in recognition but the to-be-recalled (TBRc) item is not physically present in recall. Recent accounts (Atkinson \& Juola, 1974; Bain, 1979; Humphreys, 1976; Mandler, 1972) have looked beyond this distinction. It now appears that recognition decisions are in part based on recall or something very much like recall. The basic evidence behind this assertion is as follows. After studying a pair of words $A B$, a subject is more likely to recognize $B$ when it is tested in the presence of A than when it is tested in the absence of $A$. It thus appears that information retrieved using $A$ as a cue is contributing to the recognition of $\mathrm{B}$. Furthermore, there are at least some circumstances in which the probability of retrieving this information can be estimated from overt recall probabilities (see Humphreys, 1978, and Mandler, 1980).

The order of authorship was decided by a coin toss; the authors contributed equally. Reprint requests should be addressed to either author at the Department of Psychology, University of Queensland, St. Lucia, Queensland 406 7, Australia.
3. Recognition decisions also appear to be based on information that is fundamental to recognition and, in a sense, more obligatory than the information used in recall (Bain, 1979; Geiselman \& Bjork, 1980; Humphreys, 1976; Jacoby \& Dallas, 1981; Kintsch, 1970; Mandler, 1980). The reasons behind this belief include the following: (a) It is fairly easy to reduce recall to near zero by appropriate study instructions, but these instructions still produce a level of recognition that is substantially above chance (Glenberg \& Adams, 1978; Glenberg, Smith, \& Green, 1977). (b) Following reviews by Kintsch (1970) and McCormack (1972), it was widely believed that organizational manipulations affected recall but not recognition. Although more recent evidence (some of which will be reviewed in this paper) shows that this is not true, the fact remains that there are many experimental manipulations that affect recall more than they affect recognition.

We believe that the basic problem for the recognition theorist is to weave these three observations into a coherent account. Before discussing the alternative ways in which this can be done, however, it is important to note the level of discourse that we adopt. It is our contention that the most fundamental level of analysis concerns the cues that are available or potentially available. In this we are in basic agreement with Tulving (see Tulving, 1976, and Tulving \& Thomson, 1973). Unlike Tulving, however, we believe that the next level of analysis should be in terms of the information used as evidence in the recognition decision. In this we are probably in closest agreement with Mandler (1980), although there are many differences. Mandler's discussion of his theory is partly in terms of information and partly in terms of process, although we believe that it could be translated entirely into cue and informational terms.

For us, recognition and recall are procedures, rather than processes, and we translate questions about the 
involvement of recall in recognition into questions about the cues used and the characteristics of the information recovered as evidence. Although it may be tempting to go beyond an informational analysis to speculate about memory structures and the processes that operate on them, it is our judgment, in common with others (e.g., Watkins, 1981), that such analyses outstrip our present knowledge and methodology. Thus, when we assert that a particular type of information underlies a recognition decision, we do not prefer the translation of this into the retrieval of a list marker followed by a decision process (Anderson \& Bower, 1974) over the matching of cue to trace elements (Flexser \& Tulving, 1978). In our viewpoint, these are only two of many ways to realize the informational analysis within a process model such that functional equivalence is maintained.

In order to demonstrate the utility of a cue and informational analysis, we will discuss at length two models that have a primary focus on the information used. The position developed by Mandler (1980) assumes that two types of information, familiarity and retrieval, are involved in recognition decisions. The model advocated by Bain (1979) and Humphreys (1976, 1978) also assumes that two types of information, item and relational, are involved in recognition decisions. Although the properties assigned to the two kinds of information differ in these models, detailed examination reveals that they make equivalent predictions across several recognition paradigms.

One promising difference, however, concerns the pattern of invariance found in recognition. The Humphreys/Bain model predicts that single-item recognition will remain relatively invariant across manipulations that have a substantial impact on recall. Mandler's model, however, predicts that recognition remains invariant when corrected for a retrieval component. Because of caveats associated with the models, neither is unambiguously supported by available evidence.

We will also show that both Humphreys (1976, 1978 ) and Mandler (1980) have inadequately presented their models. That is, both have phrased them in informational terms (Mandler also has included process description), but the data presented have directly concerned the cues utilized and only indirectly addressed the nature of the evidence employed in the recognition decisions. For example, although there are distinctive item and relational operations implicit in Humphreys's work, they are not sufficient to justify informational as well as cue differences (Flexser \& Tulving, 1978). Recent work, however, does sustain a broad distinction between item and relational information (Bain, 1979; Hunt \& Einstein, 1981; Leonard \& Whitten, 1983).

In a final section, we examine whether item information is descriptive of the study context (Humphreys/ Bain) or is a strength variable (such as familiarity or perceptual fluency) that correlates with, but does not describe, occurrence in the experiment (Jacoby \& Dallas, 1981; Mandler, 1980). Again, several complications prevent our drawing firm conclusions on this issue. For example, there is little evidence that study-test matching of context influences item recognition, except for stimulus parameters, such as type font (Craik \& Kirsner, 1974) and speaker's voice (Geiselman \& Bjork, 1980). Since these variables may affect the fluency of perceptual identification during the recognition test (Jacoby \& Dallas, 1981), it is not clear whether item information includes stimulus descriptions, as assumed, for example, by Geiselman and Bjork (1980), or whether it consists of nondescriptive fluency that merely correlates with experimental occurrence.

\section{HUMPHREYS/BAIN MODEL}

As a result of research commenced in the early 1970s (e.g., Light \& Carter-Sobell, 1970; Pellegrino \& Salzberg, 1975; Thomson, 1972; Tulving \& Thomson, 1971), it has been widely but prematurely accepted that the verbal context in which a word is studied can modify the encoding of that word, in terms of either its tagged meaning (Anderson \& Bower, 1974; Martin, 1975; Reder, Anderson, \& Bjork, 1974) or its episodically unique meaning (Tulving, 1976; Tulving \& Thomson, 1973), with the consequence that recognition of the TBRg word is inferior in the absence of its study context. We refer to this interpretation as the interactive hypothesis, and for reasons that will become apparent shortly, the contextual manipulation involved is called relational context.

Humphreys $(1976,1978)$ developed his model as an alternative to the interactive position. He proposed that information about a study item (say $\mathrm{A}$ ) is encoded and retrieved independently of its verbal context (B) and that, in addition, some relationship between the two items may be separately encoded (relational information). Thus, when items are tested in intact study pairings, two independent retrieval processes occur, one initiated by $A$, the other by $B$. The recognition of $A$, for example, can succeed either when item information is recovered using $\mathrm{A}$ as the cue (with a probability that is independent of the presence of $B$ ), or when relational information (implicating $A$ ) is recovered using $B$ as the cue. When $A$ is tested in the absence of $B$, however, there is only one retrieval route, and performance is correspondingly inferior. Two further points should be noted. First, in accord with Begg (1978a) and Martin (1972), Humphreys (1978) assumed that the recovery of relational information to an intralist cue requires that item information for that cue also be recovered. Second, in process terms, cues A and B are assumed to mediate trace access. In this respect, relational context may or may not be representative of other context cues. For example, if item information is contextually descriptive, environmental context might operate together with 
the test item to gain access to the trace, or it could be employed in a postaccess decision about the contextual relevance of the item.

Several observations are relevant to Humphreys's assumption that the encoding and retrieval of item information are independent of relational context. First, there now is sufficient evidence to indicate that continuity of meaning between study and test cannot account for the advantage in recognizing items in intact study pairs. After account is taken of proper controls, contextually induced variations in meaning have only small, often inconsistent, effects on recognition performance (Underwood \& Humphreys, 1979). In addition, Humphreys (1978) was successful in predicting the recognition of $A$ in its relational context $B$ from two operationally distinct procedures: the recognition of singly presented A items (which gave the probability of retrieving item information to $A$ independently of its relational context); and the recall of $A$ to $B$ as a cue (which provided the estimate of the probability of retrieving relational information to $B$ given certain assumptions about the use of overt recall for this purpose). There was a close correspondence between the predicted and obtained probabilities of recognizing in relational context, and this correspondence held across changes in criterion as determined from confidence ratings.

Further support for the encoding and retrieval of item information independently of relational context derives from the probability of recognizing at least one member of a test pair (or its complement, the probability of recognizing neither member). According to the interactive position, this probability should be greater for intact than for rearranged pairs because the presence of $B$, whether or not B is recognized in its own right, should increase the likelihood of access to the trace of $A$ relative to access either with $A$ alone or with $A$ in the context of some other (rearranged) study item. ${ }^{1}$ Humphreys's (1978) model, however, predicts no difference. Given the basic assumptions that the retrieval of $A$ to $B$ entails the recognition of $B$, and that this retrieval results in the recognition of $A$ as well, it follows that the difference between intact and rearranged pairs lies in the probability of recognizing both members, not in the probability of recognizing at least one. Again Humphreys's data were in accord with this prediction. Although there was a significant relational context effect, that is, an advantage to the recognition of items in intact over rearranged pairs (.690 vs. .541 in his 1976 data; .741 vs. .651 in his 1978 data), there was no difference in the recognition of neither member (.196 vs. 207 for intact vs. rearranged pairs in the 1976 data; .134 vs. .126 in the 1978 data).

Mandler's (1980) procedure (to be discussed in more detail later), in which pair recognition is estimated from single-item recognition and cued recall, also supports the retrieval independence position. To do this, however, Mandler not only had to assume that retrieval is inde- pendent of the presence or absence of the other member of the pair but also that the two retrieval processes are independent of the success or failure of the other. Although this latter assumption may not sound reasonable, it has in fact received substantial support (Flexser \& Tulving, 1978; Tulving \& Wiseman, 1975). The data reviewed by these authors involved the comparison of the unconditional probability of recognizing $A$ items with the probability of recognizing $A$ items conditional on their being recallable to their $B$ cues. Whereas this procedure is subject to item-selection artifacts(Hintzman, 1980; Humphreys \& Bowyer, 1980), Mandler's procedure is not. Thus, the success of Mandler's estimation procedure provides an indirect but converging line of evidence on this issue also.

At least two caveats apply to the conclusion that retrieval to a cue is independent of relational context. First, it must be acknowledged that the boundary conditions are not known. The effect may hold generally for medium- to high-frequency words that are randomly formed into pairs (Humphreys, 1976) or weak associates (Humphreys, 1978). However, it is unlikely to apply, for example, with fractured words (e.g., amnes-ty, Watkins, 1974), and may not apply when the elements, although themselves words, are subjugated to a joint meaning, as with compounds (e.g., air-port, Tulving, 1968) and idiomatic phrases (e.g., hot-dog, Horowitz \& Manelis, 1972).

Second, it cannot be assumed that overt recall will always provide a proper estimate of the retrieval of relational information. With facial stimuli (Watkins, Ho, \& Tulving, 1976; Winograd \& Rivers-Bulkeley, 1977), for example, it is very unlikely that overt recall would be measurable, yet the availability of relational information could be inferred from the ability of subjects to discriminate intact from rearranged test pairs. In other words, there are limits to parameter estimation as a means of evaluating models such as Humphreys's.

The approach adopted by Bain (1979) provides one alternative. His method was based on the assumption that if relational information is differentially recovered when recognition occurs in and out of relational context, this difference should be detectable in subsequent recall performance. His subjects studied a series of short serial lists using either item-based (e.g., rote repetition) or interitem-based (narrative) procedures, and then were tested for item recognition either in relational context (defined by the presentation of list items in input order) or not (a standard, random sequence of test items). A basic finding was that only those subjects who encoded relational (narrative) information showed the relational context advantage in recognition. The novel extension of this finding, however, was that narrative subjects tested for recognition in relational context were superior to their noncontext counterparts in list recall tested 1 week later, whereas this difference was much smaller for rote subjects. The conclusion, therefore, was that there had been greater retrieval of rela- 
tional information in the context-present test taken in the 1st week, and that this effect was proportional to the relational information made available to subjects by their study procedure.

\section{MANDLER MODEL}

The model proposed recently by Mandler (1980) is the culmination of extensive development (Mandler, 1972; Mandler, Pearlstone, \& Koopmans, 1969; Rabinowitz, Mandler, \& Barsalou, 1977; Rabinowitz, Mandler, \& Patterson, 1977), in which one objective has been the explanation of organizational effects in the recognition of individually presented items. In its present form, the model proposes that the probability of recognizing a singly tested item is the sum of the probabilities of two independent events: the recognition of the item on the basis of its familiarity, and its recognition on the basis of a retrieval involving the item. That is,

$$
P(\operatorname{RgA})=F_{a}+\left(1-F_{a}\right) R,
$$

where $F$ and $R$ refer to the familiarity and retrieval probabilities, respectively. Organizational differences in item recognition are assumed to result from variation in the retrieval component, whereas familiarity is hypothesized to reflect intraitem integration that is directly proportional to the number and recency of prior presentations of the item but is not descriptive of or unique to the contexts of those presentations.

Although familiarity and retrieval so defined have some parallels with the concepts of item and relational information employed in the Humphreys/Bain model, several differences are immediately apparent. First, whereas the notion of item information allows for the possibility of contextually unique information, familiarity specifically excludes this possibility and thus assigns any descriptive information to the retrieval component. Second, whereas both models assume that successful retrieval (recall) to a cue entails recognition of that cue, the Mandler model proposes that this is because retrieval ensures that an otherwise unrecognizable cue will be recognized, whereas the Humphreys/ Bain model assumes that cue recognition (on the basis of item information) is a prerequisite to recall. Third, and as a result of the second point, whereas the probability of recognizing an individually tested item is (usually) a direct estimate of the probability of recovering item information, Mandler's formulation requires that familiarity be estimated indirectly from the probability of recognizing the TBRg item and the probability of retrieval involving that item. Because much of the evidence cited by Mandler in support of his model is based on estimations in various data sets, many of our subsequent comments on the two models will center on his demonstrations. However, one other issue requires amplification before we proceed.

We have used the curious phrase "probability of retrieval involving the TBRg item" in reference to
Mandler's $\mathrm{R}$ for two reasons. First, Mandler made it clear that what is retrieved depends on the original form of encoding. If, for example, items have been studied in pairs, the retrieval concerned is of the holistic $A B$ pair (Mandler, 1980, p. 263, Equation 5), whereas for categorized lists, it is retrieval of the TBRg itself that is involved (p. 265). Our subsequent discussion preserves this distinction, although not for the reasons Mandler offers: Instead, we emphasize the potential for differential cuing in the two cases. Second, by assigning all contextually descriptive or unique information to the retrieval component for an item, Mandler is in danger of being unable to estimate R. Either he must assume that such information as the situational context of the experiment is contained in, or is coextensive with, the retrieval of relational information, or else estimates of the latter will underestimate the retrieval component.

\section{Items Studied and Tested as Pairs}

Mandler (1980) used the data from a large study (Mandler, Rabinowitz, \& Simon, 1981) to evaluate the predicted relative to the obtained probability of recog. nizing intact $A B$ pairs (against old-new, new-old, and new-new distractors), using obtained values for recognizing individually tested items (both A and B) and cued recall (using both $A$ and $B$ as cues) as the basis of the prediction. For this purpose, he generalized his model for the recognition of individual items (Equation 1) into the following form:

$$
\begin{gathered}
\operatorname{RgAB}=F_{a} F_{b}+\left(1-F_{a} F_{b}\right)\left(R_{a b \mid a}+\right. \\
\left.R_{a b \mid b}-R_{a b \mid a} R_{a b \mid b}\right) .
\end{gathered}
$$

In this expression, $F_{a}$ and $F_{b}$ are the familiarity values for $A$ and $B$, respectively, and $R_{a b \mid a}$ and $R_{a b / b}$ refer to the probabilities of retrieving the $A B$ unit given cues $A$ and $B$, respectively. From Equation $1, F_{a}$ is given as follows (the expression for $F_{b}$ is directly analogous):

$$
F_{a}=\frac{P(R g A)-R_{a b \mid a}}{1-R_{a b \mid a}}
$$

Given the assumptions (1) that the recognition of a single item and the recall of that item given the other member of the study pair are independent and (2) that overt recall can be used to estimate the retrieval of the $\mathrm{AB}$ unit, the retrieval expressions in Equations 2 and 3 may be estimated using the probability of recalling $B$ to $A$ as a cue $P\left(R c A_{-}\right)$and of $A$ to $B P\left(R c_{-} B\right)$ in lieu of $R_{a b \mid a}$ and $R_{a b \mid b}$, respectively. It should be noted that Mandler only acknowledged the first of these two assumptions.

The fit of the model to the Mandler et al. (1981) data was quite satisfactory. However, this result does not test Mandler's specific assumptions. If, for simplicity, we 
ignore the provision for a variable criterion that was included in Humphreys's (1978) model, the generalization of it to be recognition of intact pairs against distractors in which at least one item is new is as follows:

$$
P(\operatorname{RgAB})=I_{a} I_{b}+\left(1-I_{a}\right) I_{b} A B_{b}+\left(1-I_{b}\right) I_{a} A B_{a},
$$

where $A B_{a}$ and $A B_{b}$ refer to the probabilities of recovering relational information given recovery of item information to cues $A$ and $B$ with probability $I_{a}$ and $I_{b}$, respectively. Note that in this formulation, if, say, the recognition of $A$ fails on the basis of item information, it may succeed on the basis of relational information only if that information is recovered via the alternative pair member, $\mathrm{B}$, which in turn requires that item information be recovered to $\mathrm{B}$. Given the same two assumptions that were required for the estimation of $R$ in Mandler's model, plus the Humphreys/Bain assumption that the probability of recovering item information to $A\left(I_{a}\right)$ may be estimated by the probability of recognizing $A$ in the absence of relational context $\mathrm{P}(\operatorname{RgA})$, pair recognition can be estimated from single-item recognition and cued recall just as with Mandler's model. Although Equations 2 and 4 look somewhat different, when ob. servable variables are substituted for the theoretical parameters, the equations become identical, as is shown in Appendix A. This identity holds not only for the recognition of study pairs against distractor pairs in which at least one item is new (Humphreys, 1978), but also for all the paradigms that involve the recognition of items in relational context. In essence, this identity occurs because, in both models, retrievals proceed separately from the two cues provided and because both models assume (for opposing reasons) that the recovery of relational information to an intralist cue entails the recognition of that cue. It should also be noted that, when applied to the discrimination of intact from rearranged pairs of old items, both models reduce to Wolford's (1971) model for pair recognition, given the two assumptions required to use overt recall to estimate the recovery of relational information. Again, this identity of the models when applied to pair recognition ignores the specifics of the bias processes built into the Humphreys (1978) and Wolford (1971) formulations.

This demonstration, of course, is double-edged. Neither the Humphreys/Bain nor the Mandler formulation is uniquely supported by the relational context and derivative pair recognition studies. Rather, those studies support the hypotheses (1) that item encoding/retrieval can occur independently of relational context; (2) that the role of such context is to provide an additional retrieval route; and (3) that two types of information, however defined, are plausible extensions of this cue analysis, at least to the extent that they are anchored to operationally distinct estimation procedures.

\section{Items Studied as Pairs and Tested Singly}

For items that have been studied in pairs but then tested in the absence of relational context, the
Humphreys/Bain and Mandler models are given in Equations (5) and (6), respectively, again ignoring the scope for criterion variation incorporated into the first model (Humphreys, 1978):

$$
\begin{gathered}
P(\operatorname{Rg} A)=I_{a} \\
P(\operatorname{RgA})=F_{a}+\left(1-F_{a}\right) R_{a b \mid a} .
\end{gathered}
$$

Clearly, there is a difference between these two expressions that stems directly from the conflicting interpretations of the common assumption that recall to an intralist cue entails its recognition. In brief, Mandler's model assumes for this single-cue case that recall can provide information additional to item information, whereas the Humphreys/Bain model assumes that recall occurs to a subset of items for which item information can be recovered. One implication of Mandler's model is that item recognition should vary directly with the prevailing level of recall, other things being equal. We will return to this after consideration of Mandler's own demonstrations that concentrate on estimating $F$ conditional on recall and nonrecall.

Using data from Rabinowitz, Mandler, and Barsalou (1977), Mandler (1980) obtained estimates of the probabilities of: recognizing $\mathrm{B}, \mathrm{P}(\mathrm{RgB})$; recalling $\mathrm{A}$ to $\mathrm{B}$ as a cue, that is backward recall $P\left(R c \_B\right)$; forward recall $\mathrm{P}\left(\mathrm{RcA}_{-}\right)$; and recognition conditional on recall and nonrecall so defined. The first two predictions involved conditionalizing on backward recall and were: (1) that the probability of recognition conditional on successful backward recall $\mathrm{P}\left(\mathrm{RgB} \mid \mathrm{R} c_{-} \mathrm{B}\right)$ would be close to unity; and (2) that $F$ calculated on all the data would approximately equal the probability of recognition conditional on unsuccessful backward recall $\mathrm{P}\left(\mathrm{RgB} \mid \overline{\mathrm{Rc} \_\mathrm{B}}\right)$.

These predictions do indeed follow from Mandler's model, but they do not provide a test of the hypothesis that the test cue provides nonredundant relational information. The first prediction is common ground for the Humphreys/Bain and Mandler models, so it cannot differentiate the two opposing interpretations. With respect to the second prediction, it is readily shown that $F_{b}=P\left(R g B \mid \overline{R c \_} B\right)$ if, and only if, all recalls occur to recognized cues, which again is the common ground (the proof is given in Appendix B).

It should be noted in any event that Mandler's confirmation of these predictions depends heavily on the data set used. He restricted his analysis to the Experiment 5 data reported in Rabinowitz, Mandler, and Barsalou (1977). In that experiment, two recognition trials were given, and Mandler eliminated from the analysis those items that were recognized on only one of the two tests. For this restricted set of data (refer to the second column of Table 1), the probability of recognizing $B$ items that successfully elicit recall of $\mathrm{A}, \mathrm{P}\left(\mathrm{RgB} \mid \mathrm{Rc} \_\mathrm{B}\right)$ is .928 , approaching 1.00 as predicted. Also, the estimated value of $F(.375)$ is approximately equal to the probability of recognizing items that do not elicit recall of $\mathrm{A}\left[\mathrm{P}\left(\mathrm{RgB}_{\mathrm{g}} \mid \mathrm{Rc}_{-} \mathrm{B}\right)=.418\right]$. 
Table 1

Conditional Recognition and Estimated F Values for B Items in Experiments Reported by Rabinowitz, Mandler, and Barsalou (1977)

\begin{tabular}{|c|c|c|c|c|c|c|c|}
\hline & \multicolumn{3}{|c|}{ Study } & \multicolumn{4}{|c|}{$\begin{array}{l}\text { Reanalyzed Study } 2 \text { Using All Data } \\
\qquad\left(\mathrm{R}_{1} \mathrm{R}_{2} ; \mathrm{R}_{1} \overline{\mathrm{R}}_{2} ; \overline{\mathrm{R}}_{1} \mathrm{R}_{2} ; \overline{\mathrm{R}}_{1} \overline{\mathrm{R}}_{2}\right)\end{array}$} \\
\hline & 1 & 2 & 3 & $\mathbf{R}_{1} \cap \mathbf{R}_{2}$ & $\mathbf{R}_{1}$ & $\mathbf{R}_{2}$ & $\mathbf{R}_{1} \cup \mathbf{R}_{2}$ \\
\hline $\mathrm{P}\left(\mathrm{RgB} \mid \underline{\mathrm{R}_{\mathbf{A}} \mathrm{A}_{-}}\right)$ & .698 & .706 & .853 & .606 & .679 & .673 & .747 \\
\hline $\mathbf{P}(\mathbf{R g B} \mid \mathbf{R c A})$ & .412 & .404 & .480 & .321 & .461 & .384 & .526 \\
\hline $\mathrm{F}_{\mathrm{h}} \mid \mathrm{RcA}_{-}$ & .408 & .354 & .419 & .124 & .287 & .273 & .438 \\
\hline $\mathrm{F}_{\mathrm{b}} \mid \overline{\mathrm{RcA}}_{-}$ & .394 & .396 & .455 & .305 & .449 & .369 & .514 \\
\hline$F^{1+20-}$ & .397 & .375 & .444 & .218 & .371 & .323 & .477 \\
\hline$P\left(R g B \mid R c \_B\right)$ & .848 & .928 & .926 & .779 & .861 & .856 & .939 \\
\hline $\mathrm{P}\left(\operatorname{RgB} \mid \overline{\mathrm{Rc}} \_\mathrm{B}\right)$ & .459 & .418 & .518 & .350 & .454 & .410 & .514 \\
\hline $\mathrm{P}\left(\mathrm{RcA} \_\mid \mathrm{Rc} \_\mathrm{B}\right)$ & .955 & .991 & .968 & .979 & .979 & .979 & .979 \\
\hline $\mathrm{P}\left(\mathrm{RcA} \mathrm{A}_{-} \mid \mathrm{Rg} \mathrm{B} \cap \overline{\mathrm{R} c_{-} \mathrm{B}}\right)$ & .472 & .525 & .382 & .525 & .486 & .512 & .480 \\
\hline $\mathrm{P}\left(\mathrm{RcA} \mathrm{A}_{-} \mid \overline{\mathrm{RgB}} \cap \overline{\mathrm{Rc}} \_\bar{B}\right)$ & .345 & .479 & .270 & .455 & .474 & .457 & .479 \\
\hline
\end{tabular}

Note $-R_{1}=$ recognized on Test $1 ; R_{2}=$ recognized on Test $2 ; P\left(R g B\left(R c A_{-}\right)=\right.$probability of recognizing $B$ items that are forward recalled to $A ; P\left(\operatorname{Rg} B \mid \overline{R c A_{-}}\right)=$probability of recognizing $B$ items that are not forward recalled to $A ; F_{\mathrm{b}} \mid R c A_{-}=$estimated value of $F$ for items forward recalled; $F_{\mathrm{b}} \mid \overrightarrow{R c A}_{-}=$estimated value of $F$ for items not forward recalled; $F=$ estimated $F$ for all items; $P\left(\operatorname{Rg} B \mid R c_{-} B\right)=$ probability of recognizing items that elicit (backward) recall of $A ; P\left(\operatorname{Rg} B\left(\bar{R} c_{-} B\right)=\right.$ probability of recognizing items that do not elicit (backward) recall of $A ; P\left(R c A_{-} \mid R c-B\right)=$ probability of recalling $B$ given that $A$ was successfully recalled; $P\left(R c A_{-} \mid R g B \cap \overline{R c_{-} B}\right)=$ probability of recalling $B$ given recognition of $B$ and nonrecall of $A_{;} P\left(R c_{-} A_{-}\left(\overline{R g B} \cap \overline{R c \_} B\right)=\right.$ probability of recalling $B$ given nonrecognition of $B$ and nonrecall of $A$. Studies 1,2 , and 3 refer to Experiments 4,5 , and 6 , respectively, in Rabinowitz, Mandler, and Barsalou (1977). Study 1 uses the combined data, Study 2 the $R_{1} R_{2}$ and $\bar{R}_{1} \bar{R}_{2}$ data, and Study 3 the backward-recall-first data.

However, it will be apparent from the other columns of Table 1 that these relationships do not hold either when all the data of this experiment are analyzed, or when other experiments are considered. While Mandler argued that these predictions should be evaluated only with reliable estimates of recognition and nonrecognition (hence his use of items recognized on both or on neither of the tests), it is not clear why reliability of recall is not equally essential, nor why the more stringent predictions considered next for forward recall were evaluated in data that could not satisfy his reliability requirements. The lack of a correspondence between the observed and predicted values when the entire data base is used is, of course, embarrassing to both models. It may, however, be due to forgetting that may occur between the two test sessions or to item- and subject-selection artifacts that plague analyses based on conditional probabilities.

From a corollary of his basic model, namely, that words presented equally often will have equal values of $F$, Mandler predicted that $F$ for $B$ items that could be (forward) recalled to their $A$ cues, $F_{b} \mid R_{c} A_{-}$, would equal $F$ for $B$ items that could not be forward recalled, $\mathrm{F}_{\mathrm{b}} \mid \overline{\mathrm{R} c \mathrm{~A}}$. Again, two points need to be made. First, for both models, this prediction follows from the very plausible assumption that successful recall in one direction (backward recall in Mandler's experiment) ensures subsequent successful recall in the other direction (forward recall in Mandler's experiment). This means that, as long as a strong sequential dependency in recall is observed, a finding of equal Fs does not unambiguously test Mandler's hypothesis about Fs' depending only on presentation frequency. The mathematical proof of this assertion is given in Appendix C. Second, it will be noted from Table 1 (rows 3 and 4) that the fit of the data to Mandler's predictions is quite good for the data cited by Mandler (Studies 1, 2, and 3 in his Table 2, p. 264). However, the fit is not satisfactory when recognition in Study 2 is redefined in conformity with the two other studies (i.e., recognition on the first test, R1) nor any of the other possible definitions taken

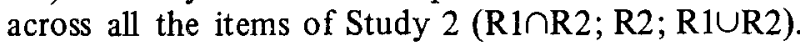
This failure of the models to fit the Study 2 data except when an arbitrary definition of recognition is used may be due to the fact that the probability of forward recall conditional on successful backward recall is somewhat less than unity or because the probability of forward recall conditional on unsuccessful backward recall and successful recognition does not equal the probability of forward recall conditional on unsuccessful recognition (the values of these statistics are given in the last three rows of Table 1). That is, if one does not accept Mandler's assumption about equal presentations leading to equal Fs, these models do not predict equal Fs unless these assumptions are met.

\section{Item Recognition Following Variation of Pair Encoding}

It is easy to specify the conditions that would lead to the rejection of the hypothesis that familiarity and retrievability occur independently to the same cue. Achieving these conditions, however, is rather difficult. What is needed is a situation in which there is a large difference in retrievability between two conditions with little or no difference in recognition. Although this situation can be achieved, there are problems in unambiguously specifying the retrievability component, and there may be a tradeoff in the encoding of the familiarity and retrievability components. For example, 
Humphreys (1976, Experiment V) had independent groups of subjects study either pairs of words or single words. The study time per word was approximately the same in the two conditions. Paired-associate instructions were used in the pair condition, whereas the subjects in the single condition were simply told to learn the words. On a subsequent single-item recognition test, the hit and false-alarm rates were slightly lower in the pair condition than in the single condition, but there was no apparent difference in sensitivity. According to Mandler (1980), in the pair condition the retrievability component would be estimated by cued recall (the TBRg item as the cue). Since this component was nonexistent in the single condition, it could be argued that recognition did not vary directly with the level of recall, contrary to his model. However, Mandler could argue that the retrievability component in the single-word condition should be estimated from free recall of the TBRg items. This ambiguity in the specification of the retrievability component makes it difficult to test the hypothesis that recognition will vary directly with recall.

Even so, a more satisfactory example comes from the comparison between separation and interactive imagery instructions applied to word pairs. The typical finding is that item recognition is either independent of method of encoding (Begg, 1978a; Bower, 1970; Dempster \& Rohwer, 1974) or slightly superior for the separation condition (Begg, 1979; McGhee, 1980). This seems to hold for both hits and false alarms, so it is not the result of a criterion shift. Conversely, cued recall (Begg, 1978a; Bower, 1970) and pair recognition (McGhee, 1980) are substantially better for the interactive condition.

This finding that recognition is relatively invariant but that recall ranges widely between conditions means that there must be a substantial dependency between familiarity and retrievability across conditions. However, in itself, this observation is not incompatible with Mandler's (1980) assumption of independence at the item level. Independence at the item level could still exist if there were a tradeoff in the encoding of $F$ and $R$. That is, separation imagery might produce a high value of $F$ but a low value of $R$, whereas interactive imagery produces the opposite effect. This may be plausible, but it does uncouple familiarity from frequency of prior occurrence and casts doubt on language frequency as a measure of preexisting familiarity. The result of the uncoupling would be to make the model more difficult to test. It is also possible that cued recall is not the sole component of retrievability in the separation-imagery condition. This possibility again makes the model very difficult to test unless these other components can be operationalized.

As a final note, it should be remembered that the object of this endeavor is to explain why single-item recognition is relatively invariant across conditions that produce dramatic changes in recall. A plausible and parsimonious explanation is that recall is simply not involved in these recognition decisions. There are, however, other conditions in which recall does appear to be involved in single-item recognition.

\section{Preexperimentally Associated Items}

We turn now to experiments in which the pairs vary in preexperimental association and are studied under general instructions to learn. A typical finding with such materials is that item recognition is greater for high than for low associates (e.g., Fisher, 1979; Fisher \& Craik, 1980; Jacoby, Craik, \& Begg, 1979; Kinsbourne \& George, 1974; Nelson, Brooks, \& Wheeler, 1975; Rosenberg, 1968; Underwood, 1976). Since the probability of cued recall varies correspondingly, it is tempting to assume along with Mandler (but contrary to the Humphreys/Bain model) that subjects recall the associate of the TBRg item, and use this recall as evidence for the item. This would be premature, however, because it ignores the likely importance of preexperimental association to the effect. If variation in the probability of cued recall alone were the critical variable (favoring high over low associates), then an analogous recognition advantage should occur for unrelated items studied under interactive imagery. The fact that it does not suggests the possibility that something else may be occurring with associated pairs. Several alternatives appear viable.

First, there is the possibility that item learning confounds what appears to be an interitem variable. As others have observed (Underwood, 1976; Underwood \& Humphreys, 1979), there may be better item encoding with strong than with weak associates, just as the categorization of items may improve their individual encoding (Bower, Clark, Lesgold, \& Winzenz, 1969; D'Agostino, 1969; Lockhart, Craik, \& Jacoby, 1976). The data reported by Fisher (1979), however, suggest that this cannot be the only effect of preexperimental association. He varied both the direction and the strength of association between word pairs and found cued recall to increase directly with the strength of association from the cue to the target item, whereas target recognition increased with the strength of the reverse association. Although the exact form of this interaction may depend on his use of a mixed list design (cf. Underwood, 1976), it suggests nonetheless that the target-to-cue association is involved in the recognition of the target.

Since this does not appear to be a "true" recall or relational information effect (it does not occur with interactive imagery), it may simply reflect the free association or "generation" of the associate to the target. The fact that such generation does not require recognition of the target (as an intralist cue) may account for the additional information apparently available with associated, but not with unrelated, pairs. Just what comprises this extra information is not known, since there are at least three ways that generation of a study associate to a target could provide additional evidence for the target: (1) Prior study of the 
pair may "prime" the preexisting association much as familiarity is hypothesized to increase with item presentation. Since equivalent priming cannot occur for a distractor-associate pair, an appropriate differential is available for use as evidence. That is, subjects might directly evaluate the strength of the primed association. (2) Targets may generate more recognizable study associates than distractors do, either because of the differential priming noted in (1) or because distractors have not been chosen so as to match targets in the normative probability of generating study associates. The latter comment applies to all experiments cited earlier. Interestingly, the study by Reardon, Da Polito, and Polzella (1974) found no associative advantage in item recognition when study pairs and distractors were interassociated. (3) Given the generation of a study associate to a target word, relational information may be recovered in the reverse direction from the associate. This effect could occur whether or not there was a parallel difference in associative priming or in the probability of generating recognizable associates, because associateTBRg relational information would not be available for distractors.

Although we cannot, at this time, distinguish between these alternatives, there is some support for two of our more important assumptions. Carroll and Kirsner (1982) looked at relational context effects on lexical decisions and on word recognition. In lexical decision, the repetition of a pair of unrelated words had no effect beyond that associated with the repetition of the individual words. When the words in a pair were associatively related, there was an additional repetition effect. Carroll and Kirsner's conclusion was that preexisting semantic relationships can be primed. They also provided some evidence to the effect that these primed associations are used in word recognition. The critical comparison here was between rearranged test pairs, the members of which had been studied with an unrelated word or with a related word. Pairing of related words at study enhanced recognition accuracy but did little to the speed with which the decision was made. The authors suggest that these primed preexperimental associations are examined (used) and that this occurs even when only one member of the pair was tested.

\section{Categorically Organized Items}

Various studies have shown that variation in the categorization of a list of items produces parallel variation in item recognition. Mandler and his colleagues, for example, have demonstrated that item recognition increases with the number of subjective categories used to sort TBRg items during study (Mandler, 1972; Mandler et al., 1969) and that this effect is more pronounced the longer the retention interval (Mandler et al., 1969). Other researchers have shown that the blocking of items by normative category during study results in better item recognition than a random study arrangement, even when the test does not preserve the input structure (Bower et al., 1969; D’Agostino, 1969; Jacoby \& Hendricks, 1973; Slamecka, 1975).

Essentially the same explanations can be canvassed as for preexperimentally associated items. It should be noted first, however, that an improvement in item learning (Bower et al., 1969; Schwartz \& Humphreys, 1972, 1976) or distinctiveness (Lockhart et al., 1976) cannot account for all the recognition data. Assuming that better learned items are responded to more quickly as well as more accurately (Murdock, 1974), the categorization advantage in recognition accuracy should occur not only with slow responses, as reported by Mandler and Boeck (1974), but, on the contrary, should be more pronounced in fast responses.

This leaves the priming of item-category associations (mechanism a), generation and recognition of the target category label (mechanism b), or generation of the category label followed by cued recall (of the target) to that label (mechanism c). We will examine the last two of these, in reverse order.

When applying his model to categorized items, Mandler (1980, p. 265) assumed that recall of the TBRg item itself determines its recognizability, not the recall of some other list item using the TBRg as a cue (as in the recognition of paired items). Furthermore, it is clear from the studies used to estimate the probability of such recall that the category names used during study are assumed to be available and to act as recall cues during recognition (Mandler \& Rabinowitz, 1981; Rabinowitz, Mandler, \& Barsalou, 1977; Rabinowitz, Mandler \& Patterson, 1977). That is,

$$
P(\operatorname{RgA})=F_{a}+\left(1-F_{a}\right) R_{a \mid c},
$$

where $R_{a \mid c}$ refers to the probability of retrieving $A$ given an input category name. Thus, Mandler's model for categorically organized items is homologous with the Humphreys/Bain model for recognition in relational context, given that item-category relational information is involved, and that the category label either is supplied by the experimenter (as in the relational context procedure) or can be generated by the subject independently of whether the TBRg item is recognizable on the basis of item information alone (mechanism $\mathrm{c}-$ see Bain, 1979).

Mandler (1980) made two further assumptions to accommodate all the data reported earlier, namely (1) that relative familiarity decays more rapidly over time than retrieval information (p. 254), thus accounting for the increase in the organizational effect over the retention interval (Mandler et al., 1969), and (2) that retrieval-mediated recognitions are slower than those based on familiarity (pp. $254 ; 268$ ), which purportedly is why Mandler and Boeck (1974) found an organizational effect only with slow responses. It can be shown that the first of these is not essential to the Humphreys/ 
Bain model, ${ }^{2}$ but the second is required if the Mandler and Boeck data are to be incorporated.

Nilsson and Shaps (1981) also have suggested that mechanisms similar to $b$ and $c$ are employed in the recognition of categorizable items. However, they have been somewhat inconsistent in their application of these mechanisms to different aspects of their data. Their experiments required subjects to study word pairs consisting of a target and a category label. Their first observation was that recognition failure was very low, and well outside the Tulving and Wiseman (1975) function. That is, subjects seldom recalled words (to their category cues) that they had not earlier recognized. In explanation, Nilsson and Shaps proposed that, whether or not a target was recognized in its own right, subjects were able to generate the category name for that target, "thereby reinstating the general contextual information necessary for recognition success" (p. 29). Since the same low level of recognition failure was observed when all distractors were from the target category (Experiment 2), it looked as though the generated category label was acting as a cue for recall of the target (mechanism $c$ ), not just as a means of eliminating distractors unrelated to the target category (a variant of mechanism $b$ that could have applied to their first experiment, in which all distractors were from nonlist categories).

However, Nilsson and Shaps (1981) overlooked this implication of their data when explaining a later observation (Experiment 3) that, during forced-choice recognition, subjects were three times more likely to select a distractor from the same category as the target than a distractor from a different (nonlist) category (cf. Mandler, 1972). In this case, their explanation assumed that generation of the category name to the target item eliminates the nontarget category distractors, thereby increasing the guessing probability for targets and the false-alarm rate to target category distractors. ${ }^{3}$ As already noted, this variant of mechanism $b$ cannot account for their Experiment 2 data, and it (or other $b$ variants) would not provide an explanation of the better discrimination of well-categorized targets from same-category distractors (D'Agostino, 1969; Slamecka, 1975). However, it should be noted that their mixeddistractors procedure could prove very useful in exploring the function of category generation during item recognition.

\section{CUE VS. INFORMATION}

The data that have been reviewed provide relatively firm evidence for the use of two cues and/or retrieval routes following categorized list learning and in the relational context paradigm. One route starts from the TBRg item, and the other route from the category name or the other member of the study pair. By itself, this observation about two cues and/or retrieval routes does not support the assumption that two kinds of information are involved in these recognition decisions, although up to this point we have tended to use the two interchangeably. Evidence on this distinction has to come from outside the parameter-fitting procedures employed by Humphreys (1978) and Mandler (1980).

To illustrate this, it is appropriate to consider the implications that can be drawn from Wolford's (1971) work. Wolford had subjects study pairs of items and then used the obtained probabilities of forward and backward recall to predict the probability of discriminating intact from rearranged pairs. Wolford found that the probability of recognizing an intact pair in such a situation was closely approximated by the following expression, where $\mathrm{g}$ is a guessing parameter:

$$
\begin{gathered}
P[\operatorname{Rg}(A B)]=1-\left[1-P\left(R_{C} A_{-}\right)\right] \\
{\left[1-P\left(R c \_B\right)\right](1-g) .}
\end{gathered}
$$

It thus looked as if intact pairs were being recognized if either the forward or the backward association existed, and furthermore it looked as if these associations were independent and could be estimated by overt recall. Because the operations of cuing in the forward and in the backward directions are so similar, there is no suggestion that the information produced in forward and backward recall is fundamentally different. Note, however, that Humphreys (1978) and Mandler (1980) were predicting the discrimination of intact from newnew or old-new pairs from single-item recognition and from the recall of one member of the study pair given the other member as a cue. At face value, these operations are quite dissimilar, so it is plausible that two types of information are involved. However, since it is equally plausible that the same trace (information) can mediate recognition and recall performance (e.g., Flexser \& Tulving, 1978), the conclusions to be drawn are the same as those supported by Wolford's work -that the cues fully specify the differences between the operations.

Better evidence is provided by situations in which both encoding conditions and testing conditions plausibly involve two types of information and they interact in predictable ways. One such situation involves a comparison of separation and interactive imagery. These encoding operations plausibly create two kinds of information (possibly nothing more than separate vs. joint traces). But, in addition, they interact disordinally with test conditions. That is, single-item recognition is better with separation imagery than with interactive imagery, whereas the reverse is true with pair recognition and cued recall. Some distinction functionally equivalent to the item/relational one appears necessary to account for these results.

Hunt and Einstein (1981) provided further support for two distinct types of information. They used an incidental-learning paradigm with orienting tests designed to enhance the encoding either of item-specific information or of similarities among items. Specifically, 
they had subjects either make pleasantness judgments about individual items or sort the items of a list into taxonomic categories. The effects of these orienting tasks depended on the degree of organization within the study list and on the nature of the test. With a freerecall test, the sorting task was better than the pleasantness task only when the study list had a low or nonobvious level of organization. With a recognition test, however, the pleasantness task was better than the sorting task for both high and low levels of study list organization. Analogously, a series of studies (Balota \& Neely, 1980; Neely \& Balota, 1981) on test expectancies has shown that subjects who have studied a list while expecting recall do better on a recall test and about as well on a recognition test as do subjects who have studied expecting recognition. Most importantly, Leonard and Whitten (1983) showed that subjects who expected recall also have more information about the order of items within a list then those who expected recognition.

Bain's (1979) results using his transfer methodology also provide evidence for the use of two kinds of information and, furthermore, link some of the information used in the relational context paradigm to recall. Briefly, an interpolated test showed positive transfer on a subsequent item-recognition test whenever the interpolated test provided experience with the TBRg items. Such experience was provided by a recognition test and a recall test, if recall was good. Positive transfer to a subsequent recall test, however, occurred only when the interpolated test plausibly involved interitem relationships. Thus, it occurred when the interpolated test was a recall test, a list-discrimination test, or an itemrecognition test, provided recognition was tested in context. If a single dimension of information was involved, then those conditions that produced positive transfer on one test should also have produced positive transfer on the other test. The fact that the effects obtained with an interpolated test of recognition in context are similar to the transfer effects with an interpolated recall test links the information used when recognition is tested in context to recall. The generality of these findings, however, remains to be determined.

Mandler (1980) also attempted to provide evidence for two types of information by showing that his concept of familiarity has different properties from recall, notably that familiarity is invariant over a variety of conditions in which recall changes. We, however, have shown that these demonstrations follow either from the assumption that a cue will be recognized whenever that cue can be used to recall the other member of the study pair, or from some very plausible sequential testing effects. Thus, these demonstrations do not support the assumption that familiarity has different properties from recall. However, Mandler and Boeck's (1974) finding that organizational differences occur only with slow recognition responses does provide some evidence for different properties. Although this finding needs to be replicated, their proposal that familiarity and retrieval have different recruitment times provides one of the best hopes for differentiating them.

Although none of the evidence that we have cited is in itself decisive, the overall picture strongly implicates two types of information, not just two retrieval routes, as being involved in the relational context paradigm. One type of information appears to be about the cooccurrence of two or more items. That is, subjects are not simply using $\mathrm{A}$ as a cue to recall $\mathrm{B}$ and then recognizing $\mathrm{B}$. This may occur in some paradigms, but in the relational context paradigm, the information used either specifies that $\mathrm{A}$ and $\mathrm{B}$ occurred together or permits that inference (e.g., subjects could be evaluating the speed or ease with which $B$ was produced in response to the presentation of A relative to other possible cues for B). This information seems to be well summed up by the term "relational information." Although its primary function is in recall and in the discrimination of intact from rearranged pairs, it can also be used to infer that a particular item occurred. The storage of this information is enhanced by interactive imagery instructions as opposed to separation imagery, by narrative instructions as opposed to rote instructions and by category judgments as opposed to pleasantness judgments, and subjects are more likely to store the information if they expect a recall test.

The other type of information used in these recognition decisions is information about the occurrence of a single item. We will refer to this type of information as item information, although we do not mean to imply by that the acceptance of all of Humphreys's (1976, 1978) assumptions. About all that can be agreed on at this stage is that item information is acquired in a more obligatory fashion than is relational information. In the Humphreys/Bain model, this obligatory characteristic will show up in the relative invariance of single-item recognition (assuming, of course, that additional retrieval routes due to preexperimental associations are not present). In the Mandler model, the obligatory component will only be observed after single-item recognition has been corrected for the retrieval component. In the Humphreys/Bain model, relational information is not recoverable to a cue unless item information is also recoverable. In the Mandler model, they are recovered independently. In most data sets, however, this difference does not lead to different predictions. Another difference between these two models, and one that is probably more testable, lies in the role of contextual stimuli. This issue will be discussed in the next section.

\section{Item Information: Contextually Descriptive or Contextually Correlated?}

In approaching this question, we assumed initially that, item recognition being contextually dependent, our task was to determine whether item or relational information was the source of that dependence and thus establish which of the two was contextually descriptive. It transpired, however, that neither the contextual 
dependence of recognition nor the assumption that such dependence implies descriptive trace information is unassailable. We examine each of these issues in turn.

The only way to determine whether a memory task is dependent on contextually descriptive trace information is to see whether that task is sensitive to the degree of match between study and test contexts. Thus, free recall is improved by the matching of physical environments at study and test (Godden \& Baddeley, 1980; Smith, 1979; Smith, Glenberg, \& Bjork, 1978), by the mental reinstatement of physical environment during recall (Smith, 1979), and by the matching of internal states (drug induced-Eich, 1980; moods-Bower, 1981). None of these manipulations, however, influences item recognition. With one exception, to be discussed later, recognition has only been shown to be affected by relational context and the matching of physical features intrinsic to item presentation (type font-Craik \& Kirsner, 1974; Kirsner, 1973; speaker's voice-Geiselman \& Bjork, 1980).

This insensitivity of recognition to context manipulations that affect recall is not in itself proof that recog. nition does not use contextually descriptive information. For example, it is fairly easy to create a model in which recall is more sensitive to the degree of contextual match than is recognition. One class of models would center on the explicitness of the cue that is provided on the recognition test (Bower, 1981; Eich, 1980; Glenberg, 1979). Another class could assume that trace decoding during recall is sensitive to the degree of matching between study and test contexts (Anderson \& Bower, 1974; Begg, 1978b). However, neither of these alone explains why recognition should be so insensitive to environmental and internal context and yet be sensitive to intrinsic features of item presentation. Perhaps the critical parameter is the density and/or locus of context reinstatement during recognition. To date, intrinsic context has been reinstated with the presentation of each item, whereas environmental and internal contexts have only been reinstated on a list-wide basis. Alternatively, contextual cues may be more effective when they subsume fewer items and/or discriminate among the to-beremembered items. There is some evidence for this with free recall (Bower, 1981; Smith, 1979), and, plausibly, there is some item specificity with intrinsic contexts. However, the recognition tasks so far employed with environmental and internal context manipulations have subsumed the entire set of TBRg items under the same contextual cues. Another possibility is that recognition context effects might be observed in latency of responding even when they are not observed in response accuracy. Finally, it may be worth noting that the increasing specificity of the noncontext cue across tasks (free recall $<$ cued recall $<$ recognition) has been confounded with the level of memory performance. Perhaps context matching has observable effects in inverse proportion to the accuracy rate, regardless of the nature of the test.
The one exception to the generalization that recognition is only sensitive to relational and intrinsic context is a study by Stern (1981). In his first experiment, subjects studied two 24-item lists and then were tested for recognition of items from both lists. For some items, correct list membership was provided, for others no information was provided, and for a few, incorrect membership accompanied the item. In comparison with the no-information condition, false information reduced recognition accuracy but correct information did not benefit performance. In addition, there was some tendency for cuing, whether correct or incorrect, to be associated with slower responding. Several points need to be made in relation to these findings:

(1) Although relational and intrinsic context can be eliminated as the basis of the effect, just what information was being used cannot be determined. It could have been the list labels alone (Anderson \& Bower, 1974), changes in background or internal stimulation between the two list presentations, or relative recency. For the moment, we will assume some form of contextually descriptive information was involved.

(2) Since most studies of context have not included a neutral (no-information) baseline, we cannot determine whether their effects are comparable to Stern's (1981) mismatch deficit, or reflect a matching benefit, or both of these. However, if we accept Geiselman and Bjork's (1980) own-voice condition as being neutral, then it looks like both gains and losses can be expected with intrinsic context, at least when the latter is defined in terms of the imaginal voice used at study and test. Geiselman and Bjork reported recognition to be greater when study and test voices matched than when they mismatched, with the self-voice condition being intermediate between the two (although not significantly different from either).

(3) Although Stern's (1981) interpretation was cast in terms of the postaccess rejection of mismatched items, a trace-access explanation cannot be eliminated. We have already mentioned several relevant variables, including the number of items subsumed under the contextual cue. In fact, we can think of the subjects in Stern's experiment, when they are given no information, as recognizing the item out of a set of 48 items ( 2 lists x 24 items each). Then when they are given correct membership information, the best they could hope to achieve would be to recognize the item out of a set of 24. The difference between recognizing an item out of set sizes of 24 and 48 could then provide an upper bound estimate of the matching advantage to be expected in Stern's paradigm. Apropo of this argument is Schulman's (1974) work on set-size effects. When retention interval and study position were controlled, he found no difference in the recognition of items from $25-, 50-$, and 100 -item lists. It may be necessary, therefore, to have many fewer items per context cue before benefits can be observed. 
(4) Even if matching benefits are observed, they need not entail a trace-access effect, as Stern (1981) assumes. We see no reason why a postaccess model like Anderson and Bower's (1972) could not account for matching benefits if the relevance of the contextual information supplied to the subject would not otherwise have been appreciated.

(5) There is the problem with match-mismatch designs of knowing whether the normal recognition process is being assisted/retarded by specific cuing or whether the cuing effects are superimposed upon, or perhaps are occurring after, normal recognition. It might be thought that this is a problem only if mismatching costs alone are observed, for a compelling explanation in this case is that subjects constrain their affirmative responses to those recognized items that also have matching contextual information. ${ }^{4}$ However, when matching is manipulated within subjects, there inevitably is an opportunity for criterion placement to produce relative benefits. Furthermore, accuracy is not the only relevant parameter of recognition performance. Stern's (1981) finding that recognition latencies were slower with both matched and mismatched context may implicate a secondary process in his experiment.

Much of the preceding discussion has assumed that intrinsic context effects are mediated by contextually descriptive information (and it bears repeating that such an assumption does not specify whether such information is used during or after trace access). However, there is an alternative interpretation. Mandler (1980, p. 256), for example, postulated that familiarity is mediated by perceptual integration, which depends on both the frequency of presentation and the consistency of stimulus input. Thus, the matching of stimulus features at study and test (Geiselman \& Bjork, 1980) is presumed to optimize a perceptual skill (see Kolers, 1976). The relative integration (Mandler, 1980) or fluency (Jacoby \& Dallas, 1981) of this skill then becomes the evidence for item recognition. That is, although one aspect of behavior (perceptual skill) is stimulus sensitive, the information it yields for item recognition is not descriptive of a particular occurrence of the item. ${ }^{5}$

Jacoby and Dallas (1981) provided support for this argument in two stages: direct evidence for perceptual fluency, and a parallel between perceptual fluency and item recognition. For the first of these, Jacoby and Dallas showed that a brief visual presentation of a long word list increased the probability of subsequent tachistoscopic word identification. This effect extended over a period of at least $24 \mathrm{~h}$, was not affected by the orienting task (semantic-nonsemantic) used during study, and was not affected by the amount of massed study time. They also reported that the effect was modality specific (prior auditory presentation did not improve visual identification).

Next, Jacoby and Dallas (1981) demonstrated several parallels between visual identification and word recognition. The most important of these was the effect of word frequency. Glanzer and Bowles (1976) had earlier shown that new high-frequency words were more likely to be falsely identified as old during a recognition task than were low-frequency words. They also showed that a single presentation increased the probability of identifying a low-frequency word as old more than it increased the corresponding probability of identifying a high-frequency word. Jacoby and Dallas confirmed these results and also showed that visual identification of nonstudied words was better for high-than for low-frequency words and that a single presentation increased the probability of visual identification more for low- than for high-frequency words. This parallel between identification and recognition is suggestive of a perceptual fluency variable that, like Mandler's (1980) familiarity, summates with and is evaluated relative to existing fluency.

The parallel goes beyond word recognition, however, because it extends to cued recall. That is, high-frequency cue words are worse cues than low-frequency cue words (Modiglioni \& Saltz, 1969; Perlmutter, Harsip, \& Myers, 1976; Saltz, 1969). If the parallel between the effects of word frequency on visual identification and word recognition implies that the same information is used in the two tasks, then this information is also used in cued recall. Mandler's (1980) recognition model, however, proposes that familiarity is retrieved independently of recall information.

In addition to the ambiguity of parallels between identification and recognition, there are divergences that require coherent explanation. For example, Kolers (1976) demonstrated that the rereading speed and the recognition of old sentences are almost independent after extended retention. Is this because differences in reading fluency are not apparent to subjects after long retention intervals (Jacoby \& Dallas, 1981, p. 337) or because they are never used in recognition? Analogously, Jacoby and Dallas (p. 33) cited evidence indicating that amnesics show fluencylike changes in performance and yet are unable to recognize old items. This could be taken to mean (as Jacoby \& Dallas proposed) that amnesics alone have difficulty using relative fluency as recognition evidence, or it could mean that this difficulty extends to normals as well.

The most striking divergence between a fluency measure and recognition memory comes from a study by Tulving, Schacter, and Stark (1982). In this study, performance on a word-fragment completion task (the subject was provided with a string of letters interspersed with blanks and had to fill in the blanks to make a word) and on a recognition test were compared after retention intervals of $1 \mathrm{~h}$ and 7 days. Two observations indicated that these performances were unrelated. First, there was a decline in recognition performance across these two retention intervals but no comparable decline in wordfragment completion. Second, word-fragment completion was statistically independent of performance on a prior reçognition test. 
Another difficulty arises from the stimulus specificity of perceptual fluency. Although some degree of specificity is central to the construct, its elimination by such relatively subtle changes as type font would mean that there are likely to be many published experiments in which its influence on item recognition was minimal. Assuming that Mandler's (1980) procedures would yield conventionally middle to high values of familiarity for such experiments, it follows either that perceptual fluency and familiarity are functionally distinct or that Mandler's procedures overestimate familiarity.

In sum, the evidence for contextual effects in recognition is limited almost exclusively to relational and intrinsic manipulations. However, the interpretation of relational and intrinsic effects in terms of descriptive or nondescriptive information is almost totally ambiguous at this time. Although we have not emphasized the point in the immediately preceding discussion, even the relational context effect can be understood in terms of a fluency differential, albeit one deriving from a descriptive (relational) trace. That is, as we noted much earher, relational information may be evaluated directly as a description of the prior $\mathrm{AB}$ occurrence or indirectly as the relative fluency with which the cue elicits the target (this being distinct from the fluency/familiarity of the target itself). It is tempting to eliminate fluency on the grounds of parsimony because it is superfluous to the stimulusspecific changes that mediate it. However, we think this would be premature, at least for perceptual fluency, which, after all, is operationally distinct from recognition. It is crucial, therefore, that the parallels and divergences between these different operations be explored thoroughly.

\section{RESEARCH PROBLEMS}

\section{Relational Context}

When a subject is asked to recognize a word B in the presence of the other member of the study pair $A$, it looks as if something very much like recall is occurring in addition to normal item recognition. That is, the recognition of $B$ in context can be predicted from separate estimates of the recognition of $B$ by itself and of recalling $B$ given $A$ as a cue. In addition, the double miss rate appears to be independent of whether the test pair is intact or rearranged. The boundary conditions for these phenomena remain to be established, and converging evidence on the issue of a recall-like process is required. Perhaps the best hope of providing this converging evidence lies in an examination of recognition latency and/or the use of response deadlines. The assumption here is that the recruitment time for the recall-like process is longer than the recruitment time for normal recognition. Given this assumption, the greater accuracy in relational context should be associated with slower responding if relational context induces recall. Additionally, if Mandler's (1980) model is correct, and if two conditions have identical recognition accuracies but differ in their cued recall, then the condition having the higher recall should be slower to recognize (its lower familiarity being offset by higher recall).

\section{Single Item Recognition of Associates or Categorizable Words}

In these paradigms, subjects may be using their preexperimental knowledge (associations, category membership) to aid them in recovering relevant information. Several mechanisms (and associated types of information) were suggested. An important first step in examining these would be to determine whether the category label or the other member of the study pair is generated (as distinct from being recalled) when subjects attempt to recognize the target. Nilsson and Shaps's (1981) procedure in which subjects are given forced-choice tests containing both related and unrelated distractors could be used here. A few variations could be introduced, such as the inclusion of unrelated distractors that do and do not belong to the same category as list words. With these procedures, there would be enough degrees of freedom not only to test the hypothesis that the category name is generated, but also to test hypotheses about how this generation provides information. Another alternative would be to look for latency differences. That is, there might be some evidence for slow accurate responses after subjects have studied pairs of associates or pairs consisting of a category name and instance. Finally, Bain's (1979) consolidation technique could be used. If, at test, subjects are generating the other member of one of these pairs, then the extra practice (experience) might show up on a delayed cued-recall test.

Generating the other member of the study pair is an unlikely possibility with weak associates, however, unless the association itself can be primed. Carroll and Kirsner (1982) presented some evidence in favor of such priming, but more evidence is required. As a first step, it would be useful to determine if there is any transfer between a study trial on a pair of weak associates and a free-association task using the stimulus terms. It would of course be necessary to ensure that subjects were not aware of any connection between the two stages of this task. Once associative priming has been operationalized, it would then be necessary to establish its role, if any, in item recognition.

\section{Cue vs. Information}

Although a strong case can be made for the use of two cues in recognizing an item tested in relational context, it is not as apparent that the information being recovered with these different cues and/or the processes employed in utilizing them are fundamentally different. Bain's (1979) consolidation technique provides one line of evidence in favor of two types of information (two different processes) rather than two cues. To date, however, this technique has been employed only in studies on the learning and retention of short serial 
lists. It remains to be determined if similar results will be found with the more usual situation, in which pairs are studied and subjects are asked to recognize items in and out of relational context. This is an especially interesting question, since it is known that, after subjects have studied a pair of words, a recognition test on single words will enhance the subsequent cued recall of those words (Humphreys \& Bowyer, 1980). This could be taken as evidence for the recovery of relational information in this situation. The retention intervals used in the studies described by Humphreys and Bowyer, however, were much shorter than those employed by Bain (1979), and in Humphreys and Bowyer's data base there is no comparison with a condition in which subjects recognized in relational context. The latency and/or response deadline studies already suggested could also provide conclusive evidence on this issue. That is, if the recovery of information using a cue other than the TBRg item takes longer than the recovery of information using the TBRg item as the cue, then two kinds of information and/or two processes are involved.

\section{Contextually Correlated or Descriptive}

Perhaps the most difficult question to answer will be whether the information used in recognition is contextually correlated or descriptive. As we have already indicated, the evidence that has been advanced on this issue is ambiguous, and we see little prospect for a definitive experiment. It is possible, however, to obtain answers to a series of questions that, when taken together, could support one or the other side of this issue. A starting point would be to determine the adequacy of Mandler's (1980) model. A strong prediction of this model is that recognition, when corrected for recall, will remain invariant. In contrast, the Humphreys/Bain model predicts that, as long as there is no relational cue or extralist retrieval route, recognition itself is more likely to remain invariant.

A related issue is whether perceptual fluency (Jacoby \& Dallas, 1981) can serve as a model for the information used in recognition. To resolve this, it will be necessary to examine very closely the parallels among measures of perceptual fluency, recognition, and cued recall. The Tulving et al. (1982) study needs to be replicated using other measures of perceptual fluency and different retention intervals. It would also be important to determine how small a change in intrinsic context (e.g., type font) is required in order to eliminate perceptual fluency. The effect of this change on recognition could then be examined. In evaluating all this evidence, it would be useful to know whether intrinsic context affects cued recall as well as recognition. If it does, the data would favor a trace-access interpretation in which contextual description, not fluency, is the information employed.

The question of whether recognition memory is affected by environmental and internal context remains central to our understanding of memory. In looking at this issue, one might start with an experiment the outcome of which most experimenters have probably taken for granted. That is, would subjects recognize words without even a minimal reinstatement of the time and circumstances in which the words had been originally encountered? If the answer is no, it would then be appropriate to determine the minimum amount of reinstatement that is needed in order to produce recognition. Further efforts to investigate the effects of environmental and internal context on recognition might use latency measures and investigate those variables we have suggested are linked with successful demonstrations of context effects in recall and recognition, particularly the item-to-context density at study and test.

Although Stern (1981) incorrectly assumed that finding costs (from mismatching) without corresponding benefits entails a postretrieval decision process, the distinction between costs and benefits is fundamental to an understanding of context effects. The effects of context on free and cued recall and on recognition cannot be compared unless it is known whether the experiments are assessing costs, benefits, or both. Although not every context paradigm permits a noinformation control, such a control should be introduced whenever possible. In this respect, the Geiselman and Bjork (1980) procedures (in which the subjects reinstated intrinsic context) could be improved with the use of a no-information control in addition to the ownvoice condition those authors employed.

A word of caution is in order here, however. It is always possible in a match/mismatch paradigm that a process that is secondary to normal recognition is introduced. In order to provide some indication of the existence of such a process, response latencies should be collected. A comparison of within-subject and betweensubject designs would also help in this regard.

The magnitude of set size effects in recognition is also bound up with the question of how large an effect should be expected from the reinstatement of context. Studies that do not find contextual matching effects would be more interpretable if the set-size effects that would be expected, given the materials and procedures employed in that study, were known.

\section{REFERENCES}

Anderson, J. R., \& Bower, G. H. Recognition and retrieval processes in free recall. Psychological Review, 1972, 79, 97-123. ANDERson, J. R., \& Bower, G. H. A propositional theory of recognition memory. Memory \& Cognition, 1974, 2, 406-412.

Atxinson, R. C., \& Juola, J. F. Search and decision processes in recognition memory. In D. H. Krantz, R. C. Atkinson, R. D. Luce, \& P. Suppes (Eds.), Contemporary developments in mathematical psychology (Vol. 1): Learning, memory, and thinking. San Francisco: Freeman, 1974.

BAHRICK, H. P. Broader methods and narrower theories for memory research: Comments on the papers by Eysenck and Cermak. In L. S. Cermak \& F. I. M. Craik (Eds.), Levels of processing in human memory. Hillsdale, N.J: Erlbaum, 1979.

BAIN, J. D. Item and relational information in recognition and 
recall. Unpublished doctoral thesis, University of Queensland, 1979.

Balota, D. A., \& Neely, J. H. Test expectancy and wordfrequency effects in recall and recognition. Journal of Experimental Psychology: Human Learning and Memory, 1980, 6, 576-580.

BEGG, I. Imagery and organization in memory: Instructional effects. Memory \& Cognition, 1978, 6, 174-183. (a)

BEGG, I. Similarity and contrast in memory for relations. Memory \& Cognition, 1978, 6, 509-517. (b)

BEGG, I. Trace loss and the recognition failure of recalled words. Memory \& Cognition, 1979, 7, 113-123.

Bowe R, G. H. Imagery as a relational organizer in associative learning. Journal of Verbal Learning and Verbal Behavior, 1970, 9, 529-533.

Bower, G. H. Mood and memory, American Psychologist, 1981, 36, 129-148.

Bower, G. H., Clark, M. C., Leggold, A. M., \& Winzenz, D. Hierarchial retrieval schemes in recall of categorized word lists. Journal of Verbal Learning and Verbal Behavior, 1969, 8, 501-506.

Carroll, M., \& Kirsner, K. Context and repetition effects in lexical decision and recognition memory. Journal of Verbal Learning and Verbal Behavior, 1982, 21, 55-69.

Craik, F. I. M., \& KirSner, K. The effect of speaker's voice on word recognition. Quarterly Journal of Experimental Psychology, 1974, 26, 274-284.

D'Agostino, P. R. The blocked-random effect in recall and recognition. Journal of Verbal Learning and Verbal Behavior, 1969, 8, 815-820.

Dempster, F. N., \& Rohwer, W. D. Component analysis of the elaborative encoding effect in paired-associate learning. Journal of Experimental Psychology, 1974, 103, 400-408.

Егсн, J. E. The cue-dependent nature of state-dependent retrieval. Memory \& Cognition, 1980, 8, 157-173.

Fisher, R. P. Retrieval operations in cued recall and recognition. Memory \& Cognition, 1979, 7, 224-231.

Fisher, R. P., \& Craik, F. I. M. The effects of elaboration on recognition memory. Memory \& Cognition, 1980, 8, 400-404.

Flexser, A. V., \& Tulving, E. Retrieval independence in recognition and recall. Psychological Review, 1978, 85, 153-171.

Geiselman, R. E., \& BuoRk, R. A. Primary versus secondary rehearsal in imagined voices: Differential effects on recognition. Cognitive Psychology, 1980, 12, 188-205.

Glanzer, M., \& Bowles, N. Analysis of the word frequency effect in recognition memory. Journal of Experimental Psychology: Human Learning and Memory, 1976, 2, 21-31.

Glenberg, A. M. Component-levels theory of the effects of spacing of repetitions on recall and recognition. Memory \& Cognition, 1979, 7, 95-112.

Glenbero, A., \& Adams, F. Type I rehearsal and recognition. Journal of Verbal Learning and Verbal Behavior, 1978, 17, 455-463.

Glenberg, A., Smith, S. M., \& Green, C. Type I rehearsal: Maintenance and more. Journal of Verbal Learning and Verbal Behavior, 1977, 16, 339-352.

Godden, D., \& BADDELEY, A. When does context influence recognition memory? British Journal of Psychology, 1980, 71 , 99-104.

Hintzman, D. L. Simpson's paradox and the analysis of memory retrieval. Psychological Review, 1980, 87, 398-410.

Honowitz, L. M., \& MANELIS, L. Toward a theory of redintegrative memory. In G. H. Bower (Ed.), The psychology of learning and motivation (Vol. 6). New York: Academic Press, 1972.

Humphreys, M. S. Relational information and the context effect in recognition memory. Memory \& Cognition, 1976, 4, 221-232.

Humphreys, M. S. Item and relational information: A case for context independent retrieval. Journal of Verbal Learning and Verbal Behavior, 1978, 17, 175-188.
Humphreys, M. S., \& Bowyen, P. A. Sequential testing effects and the relationship between recognition and recognition failure. Memory \& Cognition, 1980, 8, 271-277.

Hunt, R. R., \& Einstein, G. O. Relational and item-specific information in memory. Journal of Verbal Learning and Verbal Behavior, 1981, 20, 497-514.

JACOBY, L. L. Perceptual enhancement: Persistent effects of an experience. Journal of Experimental Psychology: Learning, Memory and Cognition, 1983, 9, 21-38.

Jacoby, L. L., Craik, F. I. M., \& BegG, I. Effects of decision difficulty on recognition and recall. Journal of Verbal Learning and Verbal Behavior, 1979, 18, 585-600.

JACOBY, L. L., \& Dallas, M. On the relationship between autobiographical memory and perceptual learning. Journal of Experimental Psychology: General, 1981, 110, 300-340.

J ACOBY, L. L., \& Hendricks, R. L. Recognition effects of study organization and test context. Journal of Experimental Psychology, 1973, 100, 73-82.

Kinsbourne, M., \& George, J. The mechanism of the word frequency effect on recognition memory. Journal of Verbal Learning and Verbal Behavior, 1974, 13, 63-69.

KinTsCH, W. Models for free recall and recognition. In D. A. Norman (Ed.), Models of human memory. New York: Academic Press, 1970.

KIRSNER, $K$. An analysis of the visual component in recognition memory for verbal stimuli. Memory \& Cognition, 1973, 1, 449-453.

KolERs, P. A. Reading a year later. Journal of Experimental Psychology: Human Learning and Memory, 1976, 2, 554-565.

Leonard, J. M., \& WhitTen, W. B. Information stored when expecting recall or recognition. Journal of Experimental Psychology: Learning, Memory and Cognition, 1983, 9, 440-455.

Light, L., \& Carter-Sobell, L. Effects of changed semantic context on recognition memory. Journal of Verbal Learning and Verbal Behavior, 1970, 9, 1-11.

Lockhart, R. S., Craik, F. I. M., \& Jacoby, L. L. Depth of processing, recognition and recall: Some aspects of a general memory system. In J. Brown (Ed.), Recall and recognition. London: Wiley, 1976.

Mandler, G. Organization and recognition. In E. Tulving \& W. Donaldson (Eds.), Organization of memory. New York: Academic Press, 1972.

MANDlER, G. Recognizing: The judgment of previous occurrence. Psychological Review, 1980, 87, 252-271.

Mandler, G., \& Boeck, W. Retrieval processes in recognition. Memory \& Cognition, 1974, 2, 613-615.

Mandler, G., Pearlstone, Z., \& Koopmans, H. J. Effects of organization and semantic similarity on recall and recognition. Journal of Verbal Learning and Verbal Behavior, 1969, 8, 410-423.

Mandler, G., \& Rabinowitz, J. C. Appearance and reality: Does a recognition test really improve subsequent recall and recognition? Journal of Experimental Psychology: Human Learning and Memory, 1981, 7, 79-90.

Mandler, G., Rabinowitz, J. C., \& Simon, R. A. Coordinate organization: The holistic representation of word pairs. American Journal of Psychology, 1981, 94, 209-222.

Martin, E. Stimulus encoding in learning and transfer. In A. W. Melton \& E. Martin (Eds.), Coding processes in human memory. Washington, D.C: Wiley, 1972.

Martin, E. Generation-recognition theory and the encoding specificity principle. Psychological Review, 1975, 82, 150-153.

McCormack, P. D. Recognition memory: How complex a retrieval system? Canadian Journal of Psychology, 1972, 26, 18-41.

MCGHEE, R. Imagery and recognition memory: The effects of relational organization. Memory \& Cognition, 1980, 8, 394-399.

Modiglioni, V., \& Saltz, E. Evaluation of a model relating Thorndike-Lorge frequency and $m$ to learning. Journal of Experimental Psychology, 1969, 82, 584-586. 
Murdock, B. B. Human memory: Theory and data. Potomac, Md: Erlbaum, 1974.

MuRdock, B. B. A theory for the storage and retrieval of item and associative information. Psychological Review, 1982, 89, 609-626.

NeELY, J. H., \& BAlotA, D. A. Test expectancy and semantic organization effects in recall and recognition. Memory \& Cognition, 1981, 9, 283-306.

Nelson, D. L., Brooks, D. H., \& Wheeler, J. W., JR. Sensory and meaning features in stimulus recognition and associative retrieval. Journal of Experimental Psychology: Human Learning and Memory, 1975, 1, 711-719.

Nilsgon, L.-G., \& Shaps, L. P. A reconstructive processing interpretation of the recognition failure phenomenon. Acta Psychologica, 1981, 47, 25-37.

Peluegrino, J. W., \& Salzbera, P. M. Encoding specificity in cued recall and context recognition. Journal of Experimental Psychology: Human Learning and Memory, 1975, 1, 261-270.

Perlmutter, J., Harsip, J., \& Myers, J. L. The role of semantic knowledge in retrieval from episodic long-term memories: Implications for a model of retrieval. Memory \& Cognition, 1976, 4, 361-368.

Rabinowitz, J. C., Mandler, G., \& Barsalou, L. W. Recognition failure: Another case of retrieval failure. Journal of Verbal Learning and Verbal Behavior, 1977, 16, 639-664.

Rabinowitz, J. C., Mandlen, G., \& Patterson, K. E. Determinants of recognition and recall: Accessibility and generation. Journal of Experimental Psychology: General, 1977, 106, 302-329.

Reardon, E., Da Polito, F., \& Polzella, D. Associative organization in recognition memory. Perceptual and Motor Skills, $1974,38,1123-1126$.

Reder, L. M., Anderson, J. R., \& Bjork, R. A. A semantic interpretation of encoding specificity. Journal of Experimental Psychology, 1974, 102, 648-656.

Rosenberg, $\mathbf{S}$. Associative facilitation in the recall and recognition of nouns embedded in connected discourse. Journal of Experimental Psychology, 1968, 78, 254-264.

SAltz, E. Thorndike-Lorge frequency and $m$ of stimuli as separate factors in paired associate learning. Journal of Experimental Psychology, 1969, 73, 473-478.

Schulman, A. I. The declining course of recognition memory. Memory Cognition, 1974, 2, 14-18.

Schwartz, R. M., \& Humphreys, M. S. Examinations of the category-recall function. American Journal of Psychology, 1972, 85, 189-200.

Schwartz, R. M., \& Humphreys, M. S. Further examinations of the category-recall function. Memory \& Cognition, 1976, 4, $655-660$.

Slamecka, N. J. Intralist cueing of recognition. Journal of Verbal Learning and Verbal Behavior, 1975, 14, 630-637.

Sмітн, S. M. Remembering in and out of context. Journal of Experimental Psychology: Human Learning and Memory, 1979, 5, 460-471.

Smith, S. M., Gleneera, A., \& Bjork, R. A. Environmental context and human memory. Memory \& Cognition, 1978, 6, 342-353.

Stzrn, L. D. Time of encoding as a retrieval cue in recognition memory. American Journal of Psychology, 1981, 94, 99-112.

Thomson, D. M. Context effects in recognition memory. Journal of Verbal Learning and Verbal Behavior, 1972, 11, 497-511.

Tulving, E. When is recall higher than recognition? Psychonomic Science, $1968,10,53-54$.

Tulvina, E. Ecphoric processes in recall and recognition. In $\mathbf{J}$. Brown (Ed.), Recall and recognition. London: Wiley, 1976.

Tulvina, E., Schacter, D. L., \& Stakx, H. A. Priming effects in word fragment completion are independent of recognition memory. Journal of Experimental Psychology: Learning, Memory and Cognition, 1982, 8, 336-342.

Tulvina, E., \& Thomson, D. M. Retrieval processes in recognition memory: Effects of associative context. Journal of Experimental Psychology, 1971, 87, 175-184.

Tulving, E., \& Thomson, D. M. Encoding specificity and re- trieval processes in episodic memory. Psychological Review, 1973, 80, 352-373.

Tulving, E., \& Wiseman, S. Relation between recognition and recognition failure of recallable words. Bulletin of the Psychonomic Society, 1975, 6, 79-82.

UNDE RWOOD, B. J. Recognition for pairs of words as a function of associative context. Journal of Experimental Psychology: Human Learning and Memory, 1976, 2, 404-412.

Underwood, B. J., \& HumphaEy, M. S. Context change and the role of meaning in word recognition. American Journal of Psychology, 1979, 92, 577-609.

WATKINs, M. J. When is recall spectacularly higher than recognition? Journal of Experimental Psychology, 1974, 102, 161-163.

Watkins, M. J. Human memory and the information-processing metaphor. Cognition, 1981, 10, 331-336.

Watkins, M. J., Ho, E., \& Tulving, E. Context effects in recognition memory for faces. Journal of Verbal Learning and Verbal Behavior, 1976, 15, 505-518.

Winograd, E., \& Rivers-Bulkeisy, N. T. Effects of changing context on remembering faces. Journal of Experimental Psychology: Human Learning and Memory, 1977, 3, 397-405.

WolForD, G. Function of distinct associations for paired-associate performance. Psychological Review, 1971, 78, 303-313.

\section{NOTES}

1. The interactive position can be made explicit if we assume that: (a) there is one probability of recognizing an item given trace access; (b) there is a lower probability of recognizing an item given no trace access; (c) access to a joint trace is involved in the recognition of members tested in intact pairs; and (d) access to the independent traces is involved in the recognition of members from rearranged pairs. With these assumptions, the invariance in the double miss rate means that the greater probability of accessing at least one of two independent traces is being exactly offset by a greater probability of accessing the joint trace given the intact test pair as a cue. This then provides us with some information on how the intact test pair is providing for access to the joint trace. In particular, we can reject a model that assumes: (a) the presentation of $A$ in the presence of $B$ on the test trial alters the encoding of $A$ so that $A$, as encoded in the presence of $B$, is a better cue for the retrieval of the $A B$ trace than is A encoded by itself; (b) at the same time, $B$, as encoded in the presence of $A$, is a better cue for the $A B$ trace than is B encoded by itself; and (c) both the encoding of A and B can be used independently as cues for the retrieval of the $A B$ trace. We cannot, however, necessarily reject models that assume that a configural representation of the test pair is used as the retrieval cue (e.g., Murdock, 1982). Nevertheless, we feel that this invariance in the double miss rate provides a challenge to any model that purports to account for the relational context effect.

2. Bain (1979) showed that an increase in the organizational effect over the retention interval does not require the assumption that familiarity decays faster than retrieval information. In fact, even the converse can apply. Suppose familiarity decays from .90 through .81 to .73 over some period, while retrieval information decays from .70 through .56 to .45 over the same period. From Equation 7, the contribution of retrieval information to item recognition occurs with probability $\left(1-F_{a}\right) R_{a \mid c}$ the values for which would be $.07, .11$, and .12 , respectively. This function reflects the increasing opportunity for retrieval to affect recognition $\left(1-F_{a}\right)$ offset by the decreasing likeli hood of retrieval $\left(R_{a \mid c}\right)$. The function will inflect as the latter overtakes the former. Even so, although there may be reasons associated with the concept of familiarity that favor the assumption that it decays more rapidly than retrieval information, this is not a necessary feature of item information.

3. To achieve the fit of their model to this $3: 1$ ratio of false alarms to target category (same) and nontarget category (different) distractors, Nilsson and Shaps (1981) not only assumed that recall to the generated category name was zero, 
but also that the probability of generating the category name was .50 . This can be determined from a full specification of their model for a forced-choice task in which there are $\mathrm{n}$ items in the target category (including the target) and $n$ items from a nonlist category. Given that $I_{a}$ is the probability of recognizing $A$ on the basis of item information alone, $G_{c \mid a}$ is the probability of generating the category name for $A$, and $C A_{c}$ is the probability of recovering category-item relational information to the category name as a cue, then the probabilities for recognizing A, and of making a false alarm to same (LS) or different (LD) category distractors are given in the following three equations, respectively:

$$
\begin{gathered}
P(\operatorname{RgA})=I_{a}+\left(1-I_{a}\right)\left\{G_{c \mid a}\left[C A_{c}+\left(1-C A_{c}\right)\left(\frac{1}{n}\right)\right]+\left(1-G_{c \mid a}\right)\left(\frac{1}{2 n}\right)\right\} \\
P(L S)=\left(1-I_{a}\right)\left[G_{c \mid a}\left(1-C A_{c}\right)\left(\frac{1}{n}\right)+\left(1-G_{c \mid a}\right)\left(\frac{1}{2 n}\right)\right] \\
P(L D)=\left(1-I_{a}\right)\left(1-G_{c \mid a}\left(\frac{1}{2 n}\right) .\right.
\end{gathered}
$$

4. Researchers often seem to presuppose that list discriminations are a subset of item recognitions. Stern (1981), for example, had subjects judge the list membership of items by restricting presented items to those that had been recognized previously. Of course, this makes sense if list discrimination is mediated by recall (of list information) to each target, and if such recall entails target recognition.

5. Jacoby (1983) recently offered an alternative account of the nature of perceptual fluency. Although speed of identification is still assumed to be used as evidence in recognition, it is now thought to be mediated by the retrieval of specific episodic memories. This conclusion was based on studies that showed that fluency was dependent on the reinstatement of aspects of the study context other than intrinsic features. Even if this dependency on context can be replicated and extended and if firm parallels can be found between perceptual identification and recognition, the relationship between these constructs would remain open. The most parsimonious explanation would be that what affects both is the use of contextually descriptive information without the additional assumption that one influences the other.

\section{APPENDIX A}

Proof that when the observable variables are substituted for the theoretical parameters in the Humphreys (1978) model and the Mandler (1980) model, the expressions for pair recognition are the same.

When the probabilities of single-item recognition $[\mathrm{P}(\mathrm{RgA})$ or $\mathrm{P}(\mathrm{RgB})]$ are substituted for the probabilities of recovering item information $\left(I_{a}\right.$ and $\left.I_{b}\right)$ and the probabilities of cued recall $\left[\mathrm{P}\left(\mathrm{RcA}_{-}\right)\right.$and $\left.\mathrm{P}\left(\mathrm{Rc}_{-} \mathrm{B}\right)\right]$ are substituted for the probabilities of recovering relational information to recognized cues $\left(\mathrm{I}_{\mathrm{a}} \mathrm{AB}\right.$ and $\left.I_{b} A B_{b}\right)$, Equation 4 in the text becomes:

$$
\begin{gathered}
P(\operatorname{Rg} A B)=P(\operatorname{Rg} A) P(\operatorname{Rg} B)+[1-P(\operatorname{Rg} A)] P(\operatorname{Rc} B)+ \\
{[1 \quad P(\operatorname{Rg} B)] P\left(R_{1} A_{-}\right) .}
\end{gathered}
$$

Now substitute Mandler's (1980) theoretical expressions for $\mathrm{P}(\mathrm{RgA})$ and $\mathrm{P}(\mathrm{RgB})$ :

$$
\begin{aligned}
P\left(R_{g A B}\right)= & \left(F_{a}+R_{a b \mid a}-F_{a} R_{a b \mid a}\right)\left(F_{b}+R_{a b \mid b}-F_{b} R_{a b \mid b}\right) \\
& +\left(1-F_{a}-R_{a b \mid a}+F_{a} R_{a b \mid a}\right) P\left(R_{-} B\right) \\
& +\left(1-F_{b}-R_{a b \mid b}+F_{b} R_{a b \mid b}\right) P\left(R_{-} A_{-}\right) .
\end{aligned}
$$

Rearranging terms, substituting $R_{a b \mid b}$ and $R_{a b \mid a}$ for $P\left(R_{-} B\right)$ and $\mathrm{P}\left(\mathrm{RcA}_{-}\right)$, respectively, and simplifying results in the following expression, which is the same as Mandler's expression for the probability of pair recognition (see Equation 2 in the text):

$$
P(R g A B)=F_{a} F_{b}+\left(1-F_{a} F_{b}\right)\left(R_{a b \mid a}+R_{a b \mid b}-R_{a b \mid a} R_{a b \mid b}\right) .
$$

\section{APPENDIX B}

Proof that $F$ calculated on all the data equals the probability of recognition conditional on unsuccessful recall $P\left(\operatorname{RgA} \mid \overline{\mathrm{RCA}} \_\right)$. Assume that $F_{a}=P\left(\operatorname{RgA} \mid \overline{R_{C A}}-\right)$.

From the definition of $\mathrm{F}_{\mathrm{a}}$ (Equation 3 in the text) and the definition of a conditional probability:

$$
\begin{aligned}
& \frac{\mathbf{P}\left(\mathbf{R g A}_{\mathbf{g}}\right)-\mathbf{P}\left(\mathbf{R c A}_{-}\right)}{1-\mathbf{P}\left(\mathbf{R c A}_{-}\right)}=\frac{\mathbf{P}\left(\mathbf{R}_{\mathbf{g A}} \cap \overline{\mathbf{R c A}_{-}}\right)}{\mathbf{P}\left(\overline{\mathbf{R c A}}_{-}\right)}
\end{aligned}
$$

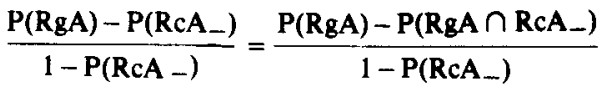

$$
\begin{aligned}
& \mathbf{P}\left(\mathbf{R c A}_{-}\right)=\mathbf{P}\left(\mathbf{R g A}_{\mathbf{B}} \cap \mathbf{R c A}_{-}\right) \\
& \text {iff } \mathbf{R} \mathbf{c A} \subseteq \mathbf{R}_{\mathbf{g A}}
\end{aligned}
$$

\section{APPENDIX C}

When Mandler (1980) tested his prediction that $F$ conditional on successful forward recall would equal $F$ conditional on unsuccessful forward recall, the testing sequence used was recognize $B$, then recall $A$ using $B$ as a cue, and then recall $B$ using $A$ as a cue. Figure 1 contains a tree diagram showing how the general model (the model for which the Humphreys/Bain and Mandler models are specific examples) is applied to this testing sequence.

In this tree diagram, if $B$ is not recognized, then the probability that $B$ will be an unsuccessful cue is 1.0 (see path 1). As we have shown, this assumption is common to both the Humphreys/Bain and the Mandler models, although for different reasons. The probability of successfully using $A$ as a cue if $B$ has been successful as a cue has also been set equal to 1.0 (see path 2). This reflects our assumption that successful recall in one direction ensures a subsequent successful recall in the other direction. Finally, we have assumed that the probability of successfully using $A$ as a cue is independent of the recognition of B, provided that B was unsuccessful as a cue (see paths 3 and 4). As Tulving and his associates (Tulving \& Wiseman, 1975; Flexser \& Tulving, 1978) have shown, this is approximately true without an intervening backward-recall test. Independence may even be more closely approximated when an intervening backward-recall test is unsuccessful, although this remains to be determined.

By Mandler's (1980) definition, 


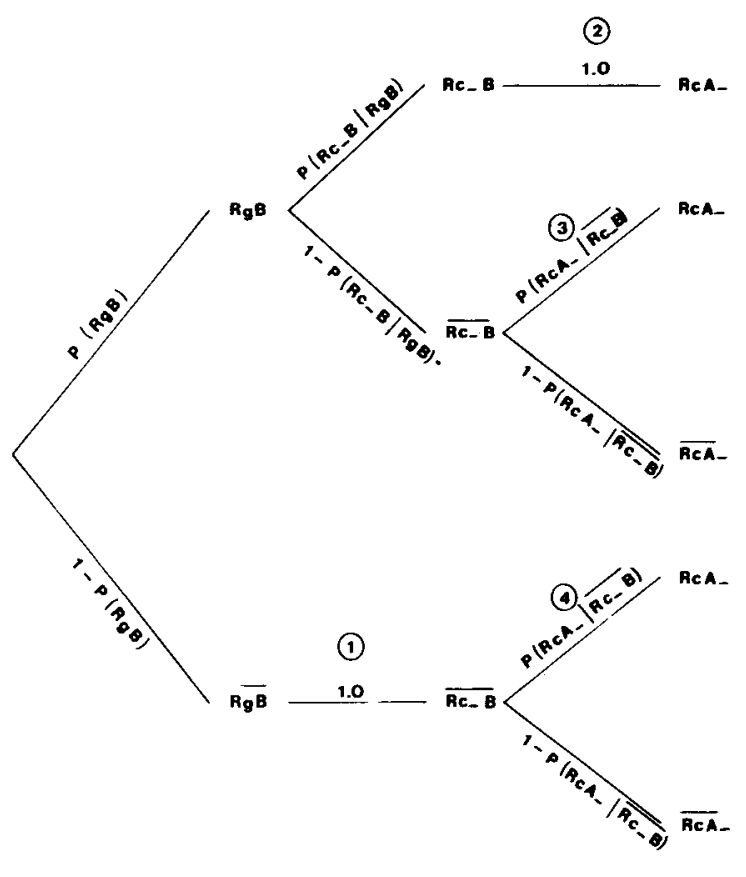

Figure 1. Tree diagram showing the application of the generalized Humphreys/Bain and Mandler models to the Rabinowitz et al. (1977, Experiment 4) testing sequence.

$$
\begin{aligned}
& F_{b} \mid R c A_{-}=\frac{P\left(R_{g B} \mid R_{c} A_{-}\right)-P\left(R_{-} B \mid R_{c} A_{-}\right)}{1-P\left(R c_{-} B \mid R_{A_{-}}\right)}
\end{aligned}
$$

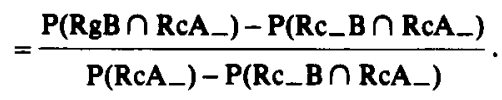

From the tree diagram it can be easily shown that

$\mathbf{P}\left(\mathbf{R c}_{-} B \cap \mathbf{R c A}_{-}\right)=\mathbf{P}\left(\mathbf{R g B}_{\mathrm{B}}\right) \mathbf{P}\left(\mathbf{R c}_{-} \mathrm{B} \mid \mathbf{R g B}\right)=\mathbf{P}\left(\mathbf{R} c_{-} B\right)$

$\mathbf{P}\left(\mathbf{R g B}_{\mathbf{B}} \cap \mathbf{R c A}_{-}\right)=\mathbf{P}\left(\mathbf{R c}_{-} \mathbf{B}\right)$

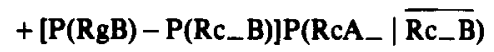

$$
\begin{aligned}
& P\left(R_{c} A_{-}\right)=P\left(R_{-} B\right)+\left[P\left(R_{g} B\right)-P\left(R_{-} B B\right)\right] P\left(R_{c} A_{-} \mid \overline{R_{-} \_B}\right) \\
& +\left[1-\mathbf{P}\left(\mathbf{R g B}_{\mathbf{B}}\right)\right] \mathrm{P}\left(\mathbf{R}_{\mathrm{A}} \mathrm{A}_{-} \mid \overline{\mathbf{R c}_{-} \mathrm{B}}\right) \text {. }
\end{aligned}
$$

When Equations 3, 4, and 5 are substituted into Equation 1, the result is Equation 5:

$$
F_{b} \mid R_{c} A_{-}=\frac{P\left(R_{g B}\right)-P\left(R_{-} B\right)}{1-P\left(R_{-} B\right)}
$$

This is of course the expression for the unconditional value of $F_{b}$, which must therefore be the same as the value of $F_{b}$ conditional on unsuccessful forward recall.

(Manuscript received August 16, 1982; revision accepted for publication May 3, 1983.) 